\title{
Effect of Alfacalcidol on Anemia in Renal Failure Patients
}

\author{
Dalal M. El-Ellisy ${ }^{1,4^{*}}$, Mohamed M. Ewais ${ }^{1,3}$, El-Sayed E. El-Awady ${ }^{4}$, Gamal A. \\ Tawfik $^{2,3}$
}

Departments of pharmacology \& Toxicology ${ }^{1}$, Internal Medicine ${ }^{2}$, Faculty of Medicine ${ }^{3}$, Faculty of Pharmacy ${ }^{4}$, Suez Canal University, Egypt.

\begin{abstract}
:
Background: Anemia is a major feature of chronic kidney disease (CKD). Additionally, secondary hyperparathyroidism (SHPT) has been associated with anemia in uremic patients. Administration of active vitamin D metabolites like alfacalcidol is established for PTH suppression and may also play a role in hematopoiesis. Aim:To investigate the effect of alfacalcidol on anemia and SHPT with end stage renal failure patients underwent hemodialysis. Subjects and Methods: In the present study 17 anemic patients over 15years, with serum level of PTH greater than $500 \mathrm{pg} / \mathrm{ml}$. The study was carried out by means of data collection and analysis of serum parathyroid hormone (PTH) and hemoglobin $(\mathrm{Hb})$ levels in these patients. Results: Low serum PTH levels were detected in uremic patients treated with alfacalcidol. Also, in these patients, $\mathrm{Hb}$ levels increased. Serum PTH and $\mathrm{Hb}$ levels were inversely correlated. Conclusions: High-dose alfacalcidol can decrease serum PTH levels and elevate $\mathrm{Hb}$ level in uremic patients showing considerable resistance to Epoetin.
\end{abstract}

Keywords: anemia, PTH, alfacalcidol, ESRD, uremic patients, SHPT

\section{Introduction:}

Many patients treated using hemodialysis remain anemic despite exogenous erythropoietin therapy, suggesting that the anemia experienced by these patients is multifactorial. Iron deficiency, infection, inflammation, and malnutrition have been implicated in this process. Additionally, secondary hyperparathyroidism (SHPT) has been associated with anemia in adults ${ }^{(1)}$.

Patients with severe SHPT show considerable resistance to Epoetin (Epo), partly because of replacement of the cellular components of the bone marrow by fibrous tissue ${ }^{(2)}$. In case of unexplained resistance to Epo, investigation of SHPT is strongly recommended, with measurement of serum parathyroid hormone (PTH), calcium and phosphate levels. Treatment of severe SHPT consists of active vitamin $D^{(1)}$.

So many studies suggested that PTH may participate in the genesis of the anemia of uremia through at least three pathways. These include inhibition of erythropoiesis, shortening survival of RBCs and inducing fibrosis of bone marrow cavity in some stage of renal failure. A possible fourth mechanism through which PTH may contribute to the anemia of uremia is its effect on platelets. PTH inhibits platelet aggregation and, as such, may play an important role in the genesis of the bleeding tendencies and the consequent blood loss in uremia ${ }^{(3)}$. Administration of active vitamin D metabolites like alfacalcidol is an es- 
tablished treatment in end-stage renal failure $^{(4)}$. Alfacalcidol not only plays a central role in calcium and phosphate homeostasis, but also control the expression of many genes in many biological actions ${ }^{(5)}$. Also Alfacalcidol may also play a role in hematopoiesis by acting directly on the progenitor cells or via stromal cells, enhancing the production of stimulatory factors ${ }^{(6)}$. The current study had investigated the effect of alfacalcidol on anemia and SHPT with end stage renal failure patients underwent hemodialysis.

\section{Subjects and methods:}

\section{Study Population:}

This study Included 17 Patients with end stage renal disease (ESRD) on regular hemodialysis in Suez Canal University Hospital, Ismailia. 9 of them were males and 8 were females. There ages were between 15-65 years. There serum level of intact PTH (iPTH) was greater than $500 \mathrm{pg} / \mathrm{ml}$ and with hemoglobin level less than $11 \mathrm{~g} / \mathrm{dl}$. None of these patients had non-renal cause of anaemia, took blood transfusions in the previous six months or had previous parathyroidectomy.

All patients received alfacalcidol i.v $(6 \mu \mathrm{g} /$ week). For the first two weeks all patients received $3 \mu \mathrm{g}$ two times/week administered after the first and the last dialysis session. Doses of alfacalcidol were increased when necessary to obtain a decrease in PTH (the maximum dose used was $14 \mu \mathrm{g} /$ week), with careful control of ionized Ca. Recombinant human erythropoietin therapy was administered from 12.5 to $50 \mathrm{U} / \mathrm{kg} / \mathrm{wk}$ subcutaneously for at least four months and also during the study ${ }^{(7)}$. Methods of Data Collection:

All patients included in the study were submitted to questionnaire (by personal interview), arterial blood pressure meas- urement and laboratory investigations including: serum PTH, Hb levels, serum $\mathrm{Ca}$ and serum $P$ monthly, serum iron, serum ferritin, Transferrin Saturation quaternary. All were examined by collecting blood sample for each patient in fasting state before dialysis.

\section{Statistical Analysis:}

Data were analyzed using statistical package for social science (SPSS) program (windows version number 10).Descriptive statistics (means, SE, and percent) were used to describe demographic data. Comparisons between the results before and after the study were performed using independent samples t-test. Data were considered statistically significant with a $\mathrm{P}$ value $<0.05$.

\section{Results:}

The study clearly shows the positive impact of high dose alfacalcidol on anemia and SHPT in ESRD patients with a good iron status and efficacious dialysis parameters. The results of the present study showed that there were a statistically significant decrease in the mean values of iPTH levels between after and before treatment with high dose of alfacalcidol i.v. $\mathrm{p}<0.05$ ) (Figure.1).

Also there were significant increase in the mean values of the serum Ca with no significant change in the mean values of the serum $P$ after four months of treatment ( $p>0.05$ ) (Figure.1). Comparing the results of laboratory data for $\mathrm{Hb}$ before and after administration of alfacalcidol for treatment of SHPT, it was found that $\mathrm{Hb}$ showed a significant increase after treatment $(p<0.05)$ (Figure.1). Also there was a significant decrease of S. Ferritin and TSAT (\%) after the study (Figures 2, 3). 


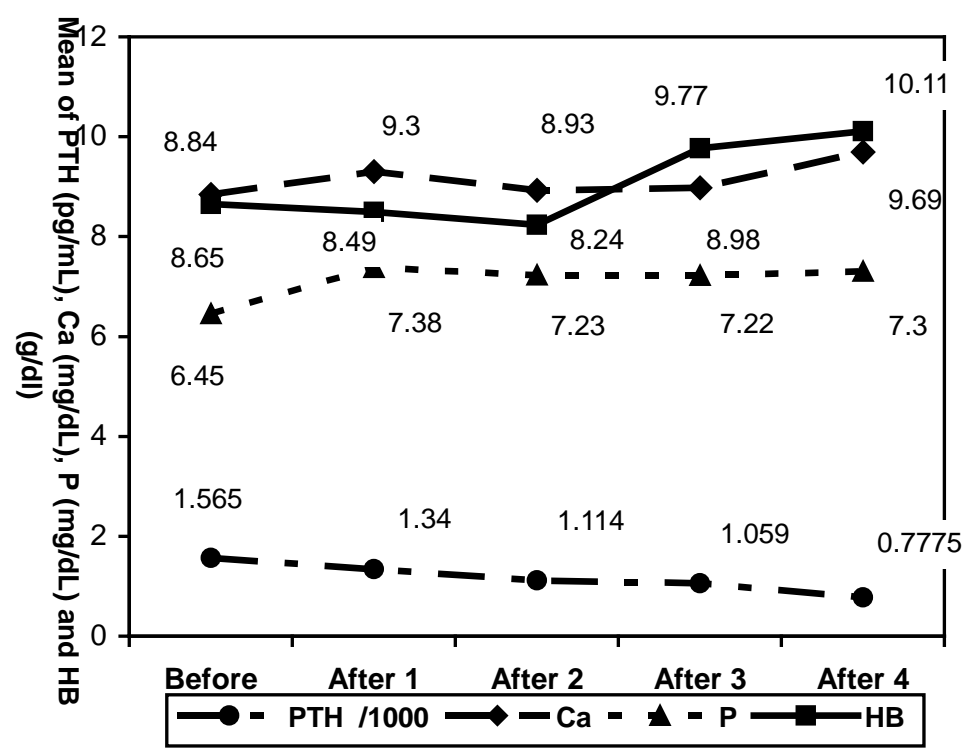

Figure 1: The change on Mean of PTH (pg/mL), Ca $(\mathrm{mg} / \mathrm{dL}), \mathrm{P}(\mathrm{mg} / \mathrm{dL})$ and HB (g/dl) before and after treatment

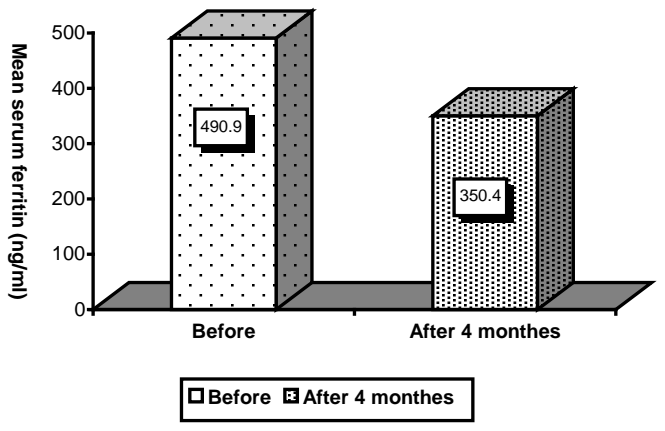

Figure 2: The change on serum ferritin $(\mathrm{ng} / \mathrm{ml})$ and after treatment

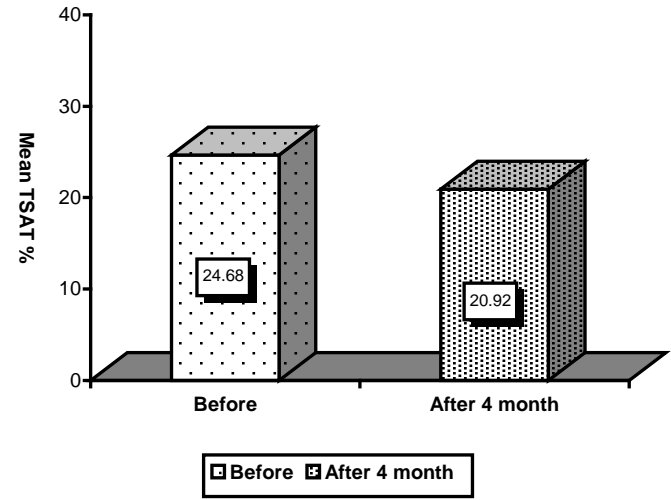

Figure 3: The change on serum TSAT\% before level before and after treatment

\section{Discussion:}

Hyperparathyroidism and anemia have been associated with uremia for many years. PTH has been considered as a uremic toxin which could interfere with the already altered hematopoiesis in dialysis patients ${ }^{(8)}$. SHPT can exacerbate anemia in CKD and particularly dialysis patients by several potential mechanisms. These include a direct toxic effect of PTH on erythropoietin synthesis, as well as on red blood cell production and survival toxic effect on bone marrow erythroid progen-itors, and an indirect effect via the induction of marrow fibrosis and interference with erythropoiesis $^{(9)}$. Several reports clearly showed an improvement in anemia after PTX ${ }^{(10)}$.

Treatment of severe SHPT consists of active vitamin D metabolites or PTX, although the marrow fibrosis, if present, may be irreversible. The finding of a progressive inability of the bone marrow to respond to Epo treatment with higher levels of PTH 
suggests the importance to prevent metabolic bone disease. Moreover, there are several reports of a beneficial action on $\mathrm{Hb}$ levels of an effective treatment of hyperpara-thyroidism ${ }^{(12)}$. Other mechanism depended on that steroid has been reported to be of therapeutic value in anemia of CKD, but it is difficult to use because of its side effect especially in children and also it was found that alfacalcidol is suspected to have anabolic steroid like effect on anemia $^{(11)}$.

According to our study, low serum iPTH levels were found in patients treated with high dose of alfacalcidol i.v. Also there were significant increase in the mean values of the serum $\mathrm{Ca}$ and no significant change in the mean values of the serum $P$ after the study. These findings are supported by others who found that Alfacalcidol significantly decreased the levels of iPTH and produced a slight increase in serum $C a$ and $P$ levels ${ }^{(12,13)}$. Thus this treatment can be utilized in those patients with significant operative risk factors to delay or even to avoid surgery.

We also found that, $\mathrm{Hb}$ levels showed significant increase after treatment and also there were significant decrease of $\mathrm{S}$. Ferritin and TSAT(\%) after the study, indicating good iron status before the study and depleted during the study improving the calculated and measured parameters of anemia. These findings were similar with those reported by others ${ }^{(14,15)}$ who reported a reverse correlation between iPTH and $\mathrm{Hb}$. These, among other factors, contribute to the severity of anemia in these patients. Conclusion: High-dose of alfacalcidol is efficient in treatment of SHPT as it decreases PTH levels and has a direct effect on serum calcium levels. Also alfacalcidol is efficient in anemic patients in ESRD as it has a direct effect on erythropoietic cells increasing $\mathrm{Hb}$ level. Finally, we recommend using high dose of alfacalcidol i.v. in anemic patients with ESRD to decrease the dose of Epo to maintain $\mathrm{Hb}$ levels thus avoiding high cost of the therapy. And also alfacalcidol treatment can avoid repeated blood transfusion for these patients.

\section{References:}

1. Brancaccio D, Cozzolino M, Gallieni M: Hyperparathyroidism and Anemia in Uremic Subjects. J Am Soc Nephrol 2004; 15: S21S24.

2. Gallienia M, Corsib C, Brancaccioa D: Hyperparathyroidism and Anemia in Renal Failure. Am J Nephrol. 2000; 20: 89-96.

3. Massry S: Pathogenesis of the anemia of uremia: role of secondary hyperparathyroidism. Kidney Int. 1983; 16: 0098-6577.

4. Llach F, Bover J.: Renal osteodystrophy. In: Brenner BM, ed. The Kidney. WB Saunders, Philadelphia. 1996; 2187-2273.

5. Brown A, Dusso A, Slatopolsky E: Vitamin D. Am J Physiol 1999; 277: 157-175.

6. Stenvinkel P, Barany P: Anemia, rHuEPO resistance, and cardiovascular disease in end-stage renal failure; link to inflammation and oxidative stress, Nephrol Dial Trans. 2002; 17: p.32

7. Fabian I, Kletter $Y$, Bleiberg I: The effect of 1,25-dihydroxy vitamin D3 on hematopoiesis in long time human bone marrow cultures. Proceeding of the society for experimental biology and medicine. 1987; 185, 434-440.

8. Malachi T, Bogin E, Gafter U, Levi J: Parathyroid hormone effect on the fragility of humane young and old red blood cells in anemia. Nephron 1989; 42: 52-57.

9. Drueke T: hyporesponsiveness to recombinant human erythropoietin. Nephrol Dial Transplant. 2001; 7: 25-28.

10. Fujita Y, Horiguchi S, kuki A: Excessive level of parathyroid hormone may induce the reduction of recombinant human erythropoietin effect on renal anemia. Miner Electrolyte Metab 1995; 21: 50-4.

11. Melamed M, Astor B, Michos E, Hostetter T, Powe N, Muntner P.: 25hydroxyvitamin D levels, race, and the progression of kidney 
disease. J Am Soc Nephrol. 2009; 20: 263126639.

12. Rix M, Eskildsen P, Olgaard K.: Effect of 18 months of treatment with alfacalcidol on bone in patients with mild to moderate chronic renal failure. Nephrol Dial Transplant. 2004; 19: 870-876.

13. Gonzáleza M., Torregrosab J., Coloméc E., Mendiac A., Pavesid M.: Efficacy of Intravenous Alfacalcidol in the Treatment of Secondary Hyper-parathyroidism in Patients on
Hemodialysis. Nephron Clin Pract 2008; 108: c141-c147.

14. Trovato G, Carpinteri G, Spina S.: Hyperparathyroidism, anemia and erythropoietin: effects on systolic fuction of dialysis patients. Nephrol Dial Transpl. 1999; 14: A190.

15. Neves P, Trivino J, Casaubon F.: Elderly patients on chronic hemodialysis: effect of secondary hyperparathyroidism on the hemoglobin level. Int Urol Nephrol. 2002; 34: 147-9. 